\title{
Treatment of intracerebellar haemorrhage: Poor outcome and high long-term mortality
}

\section{Satopää, Jarno}

2017-11-09

Satopää , J , Meretoja , A , Koivunen, R J , Mustanoja , S , Putaala , J , Kaste , M , Strbian , D , Tatlisumak, T \& Niemelä , M R 2017 , ' Treatment of intracerebellar haemorrhage: Poor outcome and high long-term mortality ' , Surgical Neurology International , vol. 8 , 272 . https://doi.org/10.4103/sni.sn

http://hdl.handle.net/10138/232138

https://doi.org/10.4103/sni.sni_168_17

publishedVersion

Downloaded from Helda, University of Helsinki institutional repository.

This is an electronic reprint of the original article.

This reprint may differ from the original in pagination and typographic detail.

Please cite the original version. 


\title{
Treatment of intracerebellar haemorrhage: Poor outcome and high long-term mortality
}

\author{
Jarno Satopää ${ }^{1}$, Atte Meretoja ${ }^{2,6}$, Riku J. Koivunen², , Satu Mustanoja², Jukka Putaala², Markku Kaste², \\ Daniel Strbian ${ }^{2}$, Turgut Tatlisumak ${ }^{2,3,4}$, Mika R. Niemelä ${ }^{1}$ \\ Departments of ${ }^{1}$ Neurosurgery, ${ }^{2}$ Neurology, Helsinki University Hospital and Clinical Neurosciences, Neurology, University of Helsinki, Helsinki, \\ Finland, ${ }^{3}$ Department of Clinical Neuroscience, Institute of Neuroscience and Physiology, Sahlgrenska Academy at University of Gothenburg, Gothenburg, \\ ${ }^{4}$ Department of Neurology, Sahlgrenska University Hospital, Gothenburg, Sweden, ${ }^{5}$ Department of Anesthesiology, Päijät-Häme Central Hospital, Lahti, Finland, \\ ${ }^{6}$ Department of Medicine at the Royal Melbourne Hospital, University of Melbourne, Parkville, VIC, Australia \\ E-mail: *Jarno Satopää - jarno.satopaa@hus.fi; Atte Meretoja - atte.meretoja@hus.fi; Riku J. Koivunen - riku.j.k@gmail.com; \\ Satu Mustanoja - satu.mustanoja@hus.fi; Jukka Putaala - jukka.putaala@hus.fi; Markku Kaste - markku.kaste@hus.fi; Daniel Strbian -daniel.strbian@hus.fi; \\ TurgutTatlisumak - turgut.tatlisumak@hus.fi; Mika R. Niemelä - mika.niemela@hus.fi \\ *Corresponding author
}

Received:03 May $17 \quad$ Accepted: 22 July $17 \quad$ Published: 09 November 17

\begin{abstract}
Background: Intracerebellar haemorrhage constitutes around $10 \%$ of all spontaneous, non-aneurysmal intracerebral haemorrhages (ICHs) and often carries a grim prognosis. In symptomatic patients, surgical evacuation is usually regarded the standard treatment. Our objective was to compare the in-hospital mortality and functional outcome at hospital discharge in either medically or surgically treated patients, and the impact of either treatment on long-term mortality after a cerebellar $\mathrm{ICH}$.

Methods: An observational, retrospective, single-centre consecutive series of 114 patients with cerebellar $\mathrm{ICH}$. We assessed the effect of different demographic factors on functional outcome and in-hospital mortality using logistic regression. We also divided the patients in medical and surgical treatment groups based on how they had been treated and compared the clinical and radiological parameters, in-hospital, and long-term mortality in the different groups.

Results: In our series, 38 patients (33.3\%) underwent haematoma evacuation and $76(66.7 \%)$ received medical treatment. Glasgow coma scale $<8$, blocked quadrigeminal cistern, and severe hydrocephalus were associated with in-hospital death or poor functional outcome at discharge (modified Rankin scale 4-6). Surgically treated patients were younger, had larger haematomas both in volume and diameter, were in a worse clinical condition, and suffered more from hydrocephalus and brainstem compression. There were no statistically significant differences in in-hospital or long-term mortality. However, the surgically treated patients remained in a poor clinical condition.
\end{abstract}

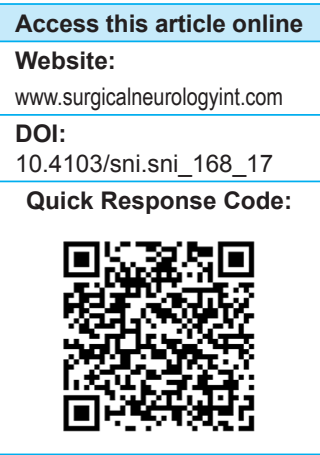

This is an open access article distributed under the terms of the Creative Commons Attribution-NonCommercial-ShareAlike 3.0 License, which allows others to remix, tweak, and build upon the work non-commercially, as long as the author is credited and the new creations are licensed under the identical terms.

For reprints contact: reprints@medknow.com

How to cite this article: Satopää J, Meretoja A, Koivunen RJ, Mustanoja S, Putaala J, Kaste M, et al.Treatment of intracerebellar haemorrhage: Poor outcome and high long-term mortality. Surg Neurol Int 2017;8:272..

http://surgicalneurologyint.com/Treatment-of-intracerebellar-haemorrhage:-Poor-outcome-and-high-long-term-mortality/ 


\section{Conclusions: Surgical treatment of cerebellar ICH can be life-saving but often leads to a poor functional outcome. New studies are needed on long-term functional outcome after a cerebellar $\mathrm{ICH}$.}

\section{KeyWords: Cerebellum, intracerebral haemorrhage, long-term mortality, outcome}

\section{INTRODUCTION}

Intracerebral hemorrhage (ICH) in the cerebellum constitutes around $10 \%$ of all "spontaneous" nontraumatic, nonaneurysmal ICHs. ${ }^{[8]}$ Since the 1970s, there has been a wide mutual consensus in the neurological and neurosurgical community that cerebellar ICHs should be operated on. However, the scientific proof is mainly based on small retrospective series with conflicting results. ${ }^{[28]}$ Hemorrhage in the posterior fossa may cause brainstem compression and lead to impaired consciousness, respiratory failure, and lower cranial nerve dysfunction. Compression or obstruction of the fourth ventricle may cause acute hydrocephalus. ${ }^{[7]}$ To relieve brainstem compression and hydrocephalus, surgeons tend to favor posterior fossa craniectomy or craniotomy with hematoma evacuation in patients with a declining level of consciousness. ${ }^{[27]}$ Some regard this counterintuitive as long-term outcomes after surgical treatment of cerebellar ICH are generally pessimistic. ${ }^{[17]}$

Our aim was to observe the short-term functional outcome and long-term mortality in medically and surgically treated patients in a consecutive single-centre series. We also searched for those demographic and radiological factors that led to poor functional outcome or death [modified Rankin Scale (mRS) 4-6] at hospital discharge.

\section{MATERIALS AND METHODS}

We performed a retrospective analysis of 1075 consecutive patients with spontaneous nonaneurysmal ICHs presenting at the neurological and neurosurgical emergency departments of our institute between January 2005 and March 2010. The patients were followed until June 2016. The catchment population is 1.8 million and the hospital has the only neurological and neurosurgical emergency rooms on a $24 / 7$ basis in the province. Patients with ICHs originating from arteriovenous malformations (AVMs), dural fistulae, or tumors were excluded from the study. The imaging data was reviewed by a neuroradiologist, and the patients with an intracerebellar hemorrhage were identified. All data were collected retrospectively from charts, electronic patient records, and imaging archives. Mortality data was collected from the National Death Registry. Institutional authorities approved the study as a registry study with no patient contact or consent, and thus all consecutive cases could be included in the study.

Immediately on arrival, all patients underwent a computerized tomography (CT) and a CT angiography to exclude aneurysms, AVMs, dural fistulae, and tumors. Glasgow coma scale (GCS) was assessed on arrival. Based on how they had been treated, we divided the patients with a cerebellar ICH in a conservative and a surgical treatment group for analyses. As there are no decisive guidelines for the treatment of cerebellar ICH, indications for surgery were not guideline- or protocol-based but determined case-by-case on an individual basis, weighing the hematoma size, declining level of consciousness, age, and possible comorbidities. As a general rule, patients with a symptomatic cerebellar ICH and declining level of consciousness were operated on, unless the clinical situation deemed unsalvageable. Deeply unconscious patients with signs of midbrain or brainstem dysfunction (unreactive, bilaterally dilated or miotic pupils, or absent corneal and oculocephalic reflexes), very high age, or severe comorbidities were treated medically. Both patient groups were treated in a specialist neurosurgical intensive care unit (ICU) or neurological acute stroke unit, with two exceptions - patients with a small hematoma and excellent clinical condition were treated in the neurological or neurosurgical wards. Deeply unconscious patients with an extensive hemorrhage were also treated in neurological or neurosurgical wards after a decision to withhold treatment. Surgically treated patients underwent a suboccipital paramedian or midline craniotomy and the hematoma was evacuated in a standard microneurosurgical manner. One patient underwent a primary bilateral decompressive craniectomy of the posterior fossa and subsequent hematoma evacuation. All patients underwent a postoperative CT scan on the first postoperative day to confirm that brainstem compression and hydrocephalus had relieved. Reoperations were recorded.

If symptomatic hydrocephalus was present, patients received an external ventricular drain (EVD). Patients with EVD but no surgical evacuation of the haematoma were included in the conservative, i.e., medical treatment group. Level of consciousness was recorded on the GCS. The GCS verbal score for intubated patients was derived using the method by Meredith. ${ }^{[19]}$ Unconscious patients were intubated and mechanically ventilated. Propofol was used for sedating the intubated patients, interrupted every 4 hours to check for the level of consciousness. 
Systolic blood pressure (BP) was kept between 120 and $160 \mathrm{mmHg}$, controlled with labetalol or clonidine, or noradrenalin in hypotensive patients. Electrolyte levels and blood gases were analyzed every 6 hours. In case of paralysis of the lower cranial nerves and dysphagia, patients received a percutaneous tracheostomy bedside at the ICU. Length of ICU and stroke unit treatment were recorded, as well as length of hospital stay until death or discharge to a rehabilitation unit or home.

On imaging studies, we assessed the maximal diameter, volume, location, and vascular territory of the hematoma. ICH volume was calculated using the $\mathrm{ABC} / 2$ method. ${ }^{[15]}$ In addition, we classified hydrocephalus on a four-grade scale by Stein et al., ${ }^{[22]}$ quadrigeminal cistern obliteration on a three-grade scale by Taneda et al. ${ }^{[24]}$ and IV ventricle compression on a three-grade scale by Kirollos et al. ${ }^{[13]}$ We used "tight posterior fossa" as a sign of brainstem compression classified as the effacement of the basal cisterns combined with obstructive hydrocephalus. ${ }^{[26]}$

As primary outcomes, we compared the in-hospital mortality, the functional outcome of medically and surgically treated patients at hospital discharge, and the impact of the chosen treatment on long-term mortality. We used the modified Rankin scale (mRS) 4-5 to classify poor functional outcome. In addition, we compared the demographics and radiological factors in surgically and medically treated patients to look for group differences. As a secondary outcome, we also assessed the effect of different demographic and radiological factors on functional outcome and in-hospital mortality.

Statistical analyses were carried out on SPSS 24.0 (IBM Corp., Armonk, NY). The ordinal and continuous variables were tested for normality. We used the Kruskal-Wallis and Mann-Whitney U tests for skewed and one-way analysis of variance (ANOVA) for normally distributed data. Pearson's Chi-square test was used to compare categorical variables between the groups. Differences in long-term mortality between the groups were assessed with Kaplan-Meier analysis. To assess the effect of categorical variables on functional outcome at discharge, we used binomial logistic regression to calculate the odds ratios. We used the Firth penalized binomial logistic regression to discard separation in the standard maximum likelihood analyses. All deaths were included regardless of the cause. A two-sided $P<0.05$ was considered significant.

\section{RESULTS}

There were 1075 consecutive patients with a spontaneous, nonaneurysmal ICH between January 2005 and March 2010 presenting at neurological and neurosurgical emergency rooms at our institute. Of these, $114(10.9 \%, 47$ females $)$ presented with a cerebellar ICH. They were aged from 30 to 94 years with a mean age of 68.3 years. Thirty-eight patients $(33.3 \%)$ were operated on and 76 (66.7\%) were treated medically, i.e., conservatively. After the primary craniotomy and hematoma evacuation, two patients had to undergo a secondary decompression of the posterior fossa to relieve brainstem compression. Three patients underwent re-evacuation because of a clinically significant residual hematoma in the postoperative scans. The reoperation rate was $13.2 \%$.

\section{Clinical and radiological data}

The surgically treated patients were significantly younger and suffered significantly less often from atrial fibrillation and hypertension. There were no other statistically significant differences in comorbidities or medications, and the premorbid functional status in mRS was similar between the treatment groups [Table 1].

The surgically treated patients were in a significantly worse clinical condition on arrival. Their ICHs were larger both in volume and diameter. In addition, they had a greater rate of hydrocephalus, quadrigeminal cistern effacement, and fourth ventricle compression. We used the criteria for "tight posterior fossa" to indirectly assess brainstem compression, and the rate was greater in the surgically treated patients [Table 2]. The hemorrhages in the medically treated group were more frequently located in the anterior cerebellar lobe, in the AICA territory, and extended to the brainstem more frequently than in the surgically treated patients (Online supplement).

\section{Treatment}

The surgically treated patients stayed longer in the intensive care and acute stroke units. Their total length of hospital stay was also longer. The rates of EVD and tracheostomy were also higher in the surgically treated patients [Table 3]. The mean interval

\begin{tabular}{|c|c|c|c|}
\hline & $\begin{array}{c}\text { Medical } \\
\text { treatment } \\
(n=76)\end{array}$ & $\begin{array}{c}\text { Surgical } \\
\text { treatment } \\
(n=38)\end{array}$ & $\boldsymbol{P}$ \\
\hline Male gender, $n(\%)$ & $45(59.2 \%)$ & $22(57.9 \%)$ & 0.893 \\
\hline Age in years, mean $(95 \% \mathrm{Cl})$ & $71.6(68.9-74.4)$ & $61.7(57.6-65.8)$ & $<0.001$ \\
\hline Atrial fibrillation & $16(20.8 \%)$ & 0 & 0.03 \\
\hline Hypertension & $54(71.1 \%)$ & $18(47.4 \%)$ & 0.013 \\
\hline Diabetes & $17(22.4 \%)$ & $3(7.9 \%)$ & 0.055 \\
\hline Liver disease & $5(6.6 \%)$ & $2(5.4 \%)$ & 0.808 \\
\hline Heavy drinking & $7(13.5 \%)$ & $5(19.2 \%)$ & 0.506 \\
\hline Warfarin & $12(15.8 \%)$ & $3(7.9 \%)$ & 0.24 \\
\hline Any antiplatelet drug & $20(26.7 \%)$ & $7(18.4 \%)$ & 0.332 \\
\hline Statins & $12(16.2 \%)$ & $5(13.2 \%)$ & 0.669 \\
\hline mRS at arrival, median (IOR) & $0(0)$ & $0(0)$ & 0.296 \\
\hline
\end{tabular}

$\mathrm{Cl}$ : Confidence interval, mRS: Modified rankin scale, IQR: interquartile range 
Table 2: Clinical and radiological characteristics at arrival in the surgically and medically treated patients. We used Pearson's Chi square test for dichotomous variables $\left({ }^{*}\right)$, one-way analysis of variance (ANOVA) for normally distributed continuous variables $(+)$, and Mann-Whitney $U$ test for skewed ordinal and continuous variables $(*)$

\begin{tabular}{|c|c|c|c|}
\hline & Medical treatment $(n=76)$ & Surgical treatment $(n=38)$ & $\boldsymbol{P}$ \\
\hline GCS on arrival, median (IQR) & $15(8-15)$ & $6(3-14)$ & $<0.001^{\ddagger}$ \\
\hline Systolic BP on arrival, mean (95\% CI) & $174(166-182)$ & $188(174-202)$ & $0.065^{\dagger}$ \\
\hline Haematoma volume in $\mathrm{ml}$, mean (95\% Cl) & $12.7(9.9-15.5)$ & $30.4(25.3-35.4)$ & $<0.001^{\ddagger}$ \\
\hline Maximal diameter in $\mathrm{mm}$, mean $(95 \% \mathrm{Cl})$ & $36.4(33.4-39.5)$ & $48.0(43.9-52.0)$ & $<0.001^{\dagger}$ \\
\hline Intraventricular blood, $n(\%)$ & $37(48.7 \%)$ & $27(71.1 \%)$ & $0.023^{*}$ \\
\hline Hydrocephalus, $n(\%)$ & & & $<0.001^{\ddagger}$ \\
\hline No & $36(47.4 \%)$ & 0 & \\
\hline Beginning & $14(18.4 \%)$ & $11(28.9 \%)$ & \\
\hline Moderate & $16(21.1 \%)$ & $16(42.1 \%)$ & \\
\hline Severe & $10(13.2 \%)$ & $11(28.9 \%)$ & \\
\hline $4^{\text {th }}$ ventricle, $n(\%)$ & & & $<0.001^{\ddagger}$ \\
\hline Open & $18(23.7 \%)$ & 0 & \\
\hline Compressed & $25(32.9 \%)$ & $5(13.2 \%)$ & \\
\hline Blocked & $33(43.4 \%)$ & $33(86.8 \%)$ & \\
\hline Quadr cistern, $n(\%)$ & & & $<0.001$ \\
\hline Open & $42(55.3 \%)$ & $2(5.3 \%)$ & \\
\hline Compressed & $20(26.3 \%)$ & $20(52.6 \%)$ & \\
\hline Blocked & $14(18.4 \%)$ & $16(42.1 \%)$ & \\
\hline Brainstem compression, $n$ (\%) & $24(31.6 \%)$ & 35 (92.1\%) & $<0.001^{*}$ \\
\hline Hematoma extension to brainstem & $9(11.8 \%)$ & $1(2.6 \%)$ & $0.101^{*}$ \\
\hline
\end{tabular}

GCS: Glasgow coma scale, IQR: Interquartile range, BP: Blood pressure, Cl: Confidence interval

Table 3: Treatment in the surgically and medically treated patients

\begin{tabular}{|c|c|c|c|}
\hline & $\begin{array}{c}\text { Medical } \\
\text { treatment }(n=76)\end{array}$ & $\begin{array}{c}\text { Surgical } \\
\text { eatment }(n=38)\end{array}$ & $P$ \\
\hline $\begin{array}{l}\text { External ventricular } \\
\text { drainage, } n(\%)\end{array}$ & $5(6.6 \%)$ & $24(63.2 \%)$ & $<0.001$ \\
\hline Tracheostomy, $n$ (\%) & $2(2.6 \%)$ & $24(63.2 \%)$ & $<0.001$ \\
\hline $\begin{array}{l}\text { Treated in ICU or acute } \\
\text { stroke unit, } n(\%)\end{array}$ & $42(55.3 \%)$ & $35(92.1 \%)$ & $<0.001$ \\
\hline $\begin{array}{l}\text { ICU and acute stroke } \\
\text { unit days, median (IOR) }\end{array}$ & $1(0-4)$ & $8(5-11)$ & $<0.001$ \\
\hline $\begin{array}{l}\text { Hospital days, } \\
\text { median (IOR) }\end{array}$ & $6.5(2-13)$ & $15.5(10-26)$ & $<0.001$ \\
\hline
\end{tabular}

between hospital admission and surgery was 22.7 hours (95\% CI: 1.2-44.2 hours). On 11 patients, the EVD was inserted before surgery, and the mean interval between hospital admission and EVD insertion was 24.7 hours (95\% CI: 6-43.4 hours).

Mortality and factors leading to poor outcome The in-hospital mortality of all patients with cerebellar ICH was 27.2\% (31 patients). Long-term mortality was $49.1 \%$ with a mean survival of 5.5 years (95\% CI: 4.5-6.6 years). In total, 76.3\% (87 patients) either died in hospital or had a poor functional outcome (mRS: 4-6) at hospital discharge.
In further analyses, we found that all patients with arrival GCS < 13 had a poor outcome (mRS: 4-6) and the in-hospital mortality in this group was 50\% $(P<0.001)$. Twenty patients were aged over 80, and 18 (90\%) were treated medically $(P=0.019)$. Only two of these 20 patients had a favorable outcome (10\%), both treated medically $(P=1)$. Ten patients had hemorrhage extending into the brainstem, and $90 \%$ of these died in hospital [Table 4].

In addition, we used univariate binomial logistic regression to assess the effect of individual variables on poor functional outcome or death (mRS: 4-6) at hospital discharge. Poor outcome was most strongly associated with (1) GCS <8, (2) blocked quadrigeminal cistern, and (3) severe hydrocephalus [Table 4 and Supplementary Tables 1 and 2].

We included the same variables in a multivariable logistic regression model and found that only two variables had a statistically significant effect on poor functional outcome or death (mRS: 4-6) at hospital discharge: (1) GCS <8 and (2) age group 65-79 years were associated with poor outcome [Table 5].

Short- and long-term outcomes after surgical or conservative treatment

The in-hospital mortality was $31.6 \%$ (24 patients) in the medically and $18.4 \%$ (7 patients) in the surgically treated 
Table 4: Results of univariate logistic regression on poor functional outcome and mortality (modified Rankin Scale 4-6)

\begin{tabular}{cccccc}
\hline Variable & $\begin{array}{c}\text { Good } \\
\text { outcome, } \\
n(\%)\end{array}$ & $\begin{array}{c}\text { Poor } \\
\text { outcome, } \\
n(\%)\end{array}$ & Odds & ratio & \\
\hline
\end{tabular}

\begin{tabular}{lccccc}
\hline Age group & & & & \\
Under 50 & $3(27.3 \%)$ & $8(72.7 \%)$ & Ref. & \\
$50-64$ & $13(39.4 \%)$ & $20(60.6 \%)$ & 0.625 & $0.134-2.46$ & 0.511 \\
$65-79$ & $9(18.0 \%)$ & $41(82.0 \%)$ & 1.799 & $0.385-7.24$ & 0.432 \\
Over 80 & $2(10 \%)$ & $18(90 \%)$ & 3.046 & $0.498-21.5$ & 0.225 \\
GCS at arrival & & & & & \\
$13-15$ & $27(42.2 \%)$ & $37(57.8 \%)$ & Ref. & & \\
$9-12$ & 0 & $6(100 \%)$ & 11 & $1.25-1450$ & 0.027 \\
$3-8$ & 0 & $44(100 \%)$ & 63.81 & $8.41-8193$ & $<0.001$
\end{tabular}

Comorbidities

Hypertension $18(25.0 \%) \quad 54(75.0 \%) \quad 0.835 \quad 0.331-2.01 \quad 0.692$

Diabetes $\quad 8(40 \%) \quad 12(60 \%) \quad 0.380 \quad 0.14-1.06 \quad 0.065$

$\begin{array}{llllll}\text { Atrial fibrillation } \quad 4(25.0 \%) & 12(75.0 \%) & 0.876 & 0.286-3.14 & 0.826\end{array}$

Liver disease $\quad 2(28.6 \%) \quad 5(71.4 \%) \quad 0.6890 .155-4.01 \quad 0.646$

Ventricular blood $\quad 5(7.8 \%) \quad 59(92.2 \%) \quad 8.542 \quad 3.23-26.3<0.001$

Brainstem $\quad 3(5.1 \%) \quad 56(94.9 \%) \quad 12.55 \quad 4.21-49.7<0.001$

compression

Volume $>10 \mathrm{ml} \quad 9(12.9 \%) \quad 61(87.1 \%) \quad 4.517 \quad 1.87-11.6 \quad 0.001$

Diameter $>3 \mathrm{~cm} \quad 11(13.1 \%) \quad 73(86.9 \%) \quad 7.272 \quad 2.89-19.2<0.001$

$\begin{array}{llllll}\text { Extension to } & 0 & 10(100 \%) & 7.448 & 0.905-967 & 0.066\end{array}$

brainstem

Hydrocephalus

No

\begin{tabular}{lccccc} 
Beginning & $5(20 \%)$ & $20(80 \%)$ & 4.632 & $1.55-15.7$ & 0.005 \\
Moderate & $2(6.3 \%)$ & $30(93.8 \%)$ & 15.17 & $4.15-82.6$ & $<0.001$ \\
Severe & 0 & $21(100 \%)$ & 53.41 & $6.46-6974$ & $<0.001$ \\
$\begin{array}{l}4^{\text {th }} \text { ventricle } \\
\text { Open }\end{array}$ & $22(50 \%)$ & $22(50 \%)$ & Ref. & & \\
Compressed & $5(12.5 \%)$ & $35(87.5 \%)$ & 5.557 & $1.66-20.9$ & 0.005 \\
Blocked & 0 & $30(100 \%)$ & 27.44 & $7.87-113$ & $<0.001$ \\
Quadrigeminal & & & & & \\
cistern & & & & & \\
Open & $13(72.2 \%)$ & $5(27.8 \%)$ & Ref. & & \\
Compressed & $9(30 \%)$ & $21(70 \%)$ & 6.456 & $2.34-20.6$ & $<0.001$ \\
Blocked & $5(7.6 \%)$ & $61(92.4 \%)$ & 61.01 & $7.68-7903$ & $<0.001$ \\
Surgical treatment & $4(10.5 \%)$ & $34(89.5 \%)$ & 3.209 & $1.16-10.9$ & 0.024 \\
\hline Cl: Confidence interval, GCS: Glasgow coma scale & & &
\end{tabular}

patients, however, the difference was not statistically significant $(P=0.137)$. Long-term mortality was $50 \%$ in the medically and $47.4 \%$ in the surgically treated patients $(P=0.791)$. The mean follow-up length was 27.3 months (95\% CI: 20.7-33.8 months) in the medically and 45.7 months (95\% CI: 31.9-59.6 months) in the surgically treated patients. The difference was statistically significant $(P=0.005)$. In Kaplan-Meier analysis, we did not find a statistically significant difference in the long-term mortality between the treatment groups $(P=0.184)$ [Figure 1$]$.
Table 5: The effect of demographic and radiological factors on poor functional outcome or mortality at discharge (modified Rankin Scale 4-6) in multivariable logistic regression

\begin{tabular}{|c|c|c|c|}
\hline Variable & Odds ratio & $95 \% \mathrm{CI}$ & $\boldsymbol{P}$ \\
\hline \multicolumn{4}{|l|}{ Age group } \\
\hline Under 50 & reference & & \\
\hline $50-64$ & 1.647 & $0.064-626$ & 0.765 \\
\hline $65-79$ & 113.2 & $2.27-12700000$ & 0.012 \\
\hline Over 80 & 48.04 & $0.812-6200000$ & 0.067 \\
\hline \multicolumn{4}{|l|}{ GCS at arrival } \\
\hline $13-15$ & reference & & \\
\hline $8-12$ & 9.767 & $0.345-2180$ & 0.175 \\
\hline $3-7$ & 366.1 & $1.84-3270000$ & 0.023 \\
\hline Ventricular blood & 11.31 & $0.838-3530$ & 0.073 \\
\hline Brainstem compression & 6.586 & $0.293-3230$ & 0.236 \\
\hline Volume $>10 \mathrm{ml}$ & 0.399 & $0.017-5.6$ & 0.496 \\
\hline Diameter $>3 \mathrm{~cm}$ & 3.145 & $0.337-52.9$ & 0.317 \\
\hline Extension to brainstem & 5.094 & $0.045-5550$ & 0.51 \\
\hline \multicolumn{4}{|l|}{ Hydrocephalus } \\
\hline No & reference & & \\
\hline Beginning & 5.589 & $0.401-2280$ & 0.211 \\
\hline Moderate & 8.82 & $0.441-799$ & 0.167 \\
\hline Severe & 90.83 & $0.853-1580000$ & 0.06 \\
\hline \multicolumn{4}{|l|}{$4^{\text {th }}$ ventricle } \\
\hline Open & reference & & \\
\hline Compressed & 3.939 & $0.51-51.5$ & 0.202 \\
\hline Blocked & 0.3738 & $0-17.2$ & 0.631 \\
\hline \multicolumn{4}{|l|}{ Quadrigeminal cistern } \\
\hline Open & reference & & \\
\hline Compressed & 1.068 & $0.063-100$ & 0.965 \\
\hline Blocked & 1.635 & $0.008-2400$ & 0.851 \\
\hline Surgical treatment & 1.98 & $0.098-1010$ & 0.662 \\
\hline
\end{tabular}

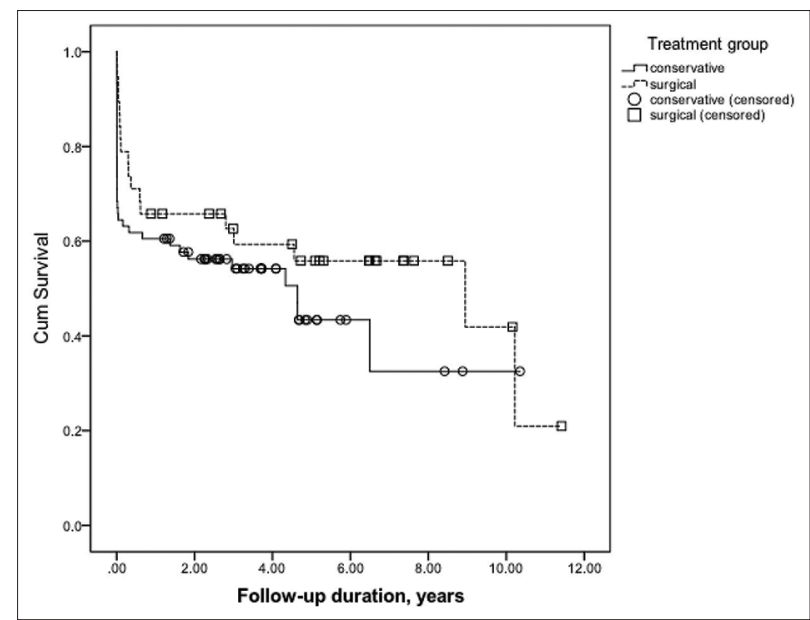

Figure I: Kaplan-Meier analysis of the long-term mortality in the different treatment groups. The difference was statistically insignificant $(P=0.184)$

However, the clinical outcome of the surviving patients at hospital discharge was significantly worse in the surgically 


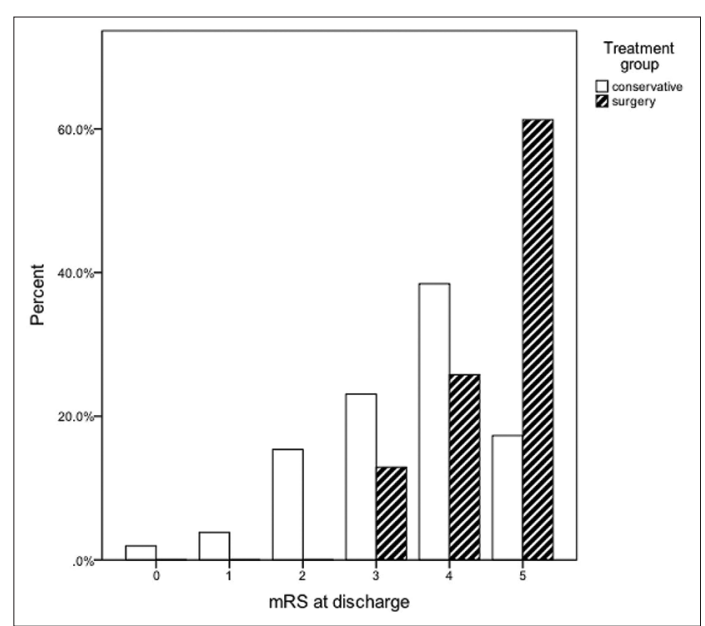

Figure 2: Functional outcome of the surviving patients $(n=\mathbf{3 0}$ in operative group, $n=\mathbf{5 3}$ in conservative group) at hospital discharge. The error bars represent $95 \%$ confidence intervals. The difference was statistically significant $(P<0.00 I)$

treated group - the median mRS with interquartile ranges were 4 (3-4) in the medically and 5 (4-5) in the surgically treated group [Figure 2]. The difference was statistically significant $(P<0.001)$. The incidence of lower cranial nerve palsy and tracheostomy in the surviving patients was $63.2 \%$ in the surgically and $2.6 \%$ in the medically treated group $(P<0.001)$. In addition, 69.3\% (53 patients) of the conservatively and $89.5 \%$ (34 patients) of the surgically treated patients died in the hospital or had a poor functional outcome (mRS: 4-6) $(P=0.019)$.

\section{DISCUSSION}

In this observational study of 114 consecutive cerebellar ICH patients, we compared the outcome of medically and surgically treated patients. Not surprisingly, the groups had significant differences. The surgically treated patients were younger, had larger hemorrhages both in volume and diameter, were in a worse clinical condition, and suffered more from hydrocephalus and brainstem compression. Majority of the surgically treated patients were first observed before proceeding to surgery, the mean interval between hospital admission and surgery being 22.7 hours. In addition, older patients with numerous comorbidities were more frequently treated medically.

Low admission GCS, increasing age, and severe hydrocephalus were associated with in-hospital mortality or poor functional outcome. Due to the generally accepted tendency for surgical treatment in symptomatic patients with a declining level of consciousness, there was a strong selection bias towards patients with larger ICHs and more severe symptoms in the surgical group.

There were no statistically significant differences in neither in-hospital nor long-term mortality, although we saw a nonsignificant trend towards better survival in the surgical treatment group. However, the operated patients more often remained in a poor clinical condition. Sixty percent of the surviving surgically treated patients needed a tracheostomy because of lower cranial nerve palsy. Unfortunately, we do not have data on the duration of tracheostomy treatment.

Cerebellar ICH is usually considered an especially deadly stroke subtype because of frequent brainstem compression and high risk of obstructive hydrocephalus. Before CT became widely available, cerebellar ICH was a silent killer - patients deteriorated rapidly and the diagnosis was often made postmortem. ${ }^{[7]}$ In 1978, Little et al. showed in a case series of 10 patients that patients with cerebellar ICHs over $3 \mathrm{~cm}$ in diameter benefited from surgical evacuation, whereas smaller could be treated medically. ${ }^{[16]}$ Since then, surgical hematoma evacuation or posterior fossa decompression has been the standard treatment in cerebellar ICH. Even today, due to the low incidence, literature on cerebellar ICH is still based on small, retrospective single-centre cohorts. ${ }^{[28]}$

The current recommendations for operative treatment vary in the literature. Numerous different criteria have been suggested for surgical evacuation or decompression: hematoma diameter $>3 \mathrm{~cm},{ }^{[16]}$ patients with brainstem compression, ${ }^{[5,26]}$ patients with GCS $4-13$ and hematoma diameter $>40 \mathrm{~mm},{ }^{[14]}$ patients with a deteriorating level of consciousness and hematoma volume $>10 \mathrm{~cm}^{3},{ }^{[9]}$ and even operating all patients with a cerebellar ICH has been suggested. ${ }^{[2]}$ Some authors do not recommend surgical treatment at all because of poor long-term results. ${ }^{[4]}$ It has been shown that clinicians usually tend to wait until clinical deterioration, and then proceed to operative treatment, especially in patients under 70 years old. ${ }^{[27]}$ The current treatment guidelines have contrasting recommendations regarding treatment of cerebellar ICH. European Stroke Organisation (ESO) treatment guidelines did not find strong evidence on when, how, or to whom surgical evacuation or decompression should be performed. ${ }^{[23]}$ American Heart Association (AHA) guidelines recommend evacuation of cerebellar ICH in patients declining neurologically or suffering from brainstem compression and/or acute hydrocephalus. ${ }^{[10]}$

Published results on long-term outcome after cerebellar ICH are rare. In Uppsala, Sweden, 62\% of the patients had either died or had an unfavorable functional outcome in long-term (70 months) follow-up. ${ }^{[25]}$ Dolderer et al. suggested that surgical treatment was an independent predictor for poor functional outcome in long-term (49 months) follow-up and we made the same observation. ${ }^{[4]}$ In their series, only $14 \%$ of the surgically treated patients had a favorable outcome. Pong showed that $56.7 \%$ of surviving patients had an unfavorable outcome (modified Rankin scale $>2$ ) at 6 months. ${ }^{[21]}$ However, some authors have observed good long-term 
results after cerebellar ICH. ${ }^{[2,3]}$ In our series, long-term mortality was $50 \%$ in the medically and $47.4 \%$ in the surgically treated patients, with a mean survival time of 5.5 years. The high long-term mortality in the surgically treated patients may be caused by the high incidence of lower cranial nerve dysfunction at discharge and subsequent risk of aspiration and pneumonia, at least partially.

We used mRS 4-5 as a criterion for poor functional outcome at discharge because of the known severe morbidity of the surviving patients. ${ }^{[21]}$ The incidence of good functional outcome at discharge was very low, 30.7\% in the medically and even lower, $10.5 \%$ in the surgically treated patients. Age was associated with poor functional outcome or death in the multivariable logistic regression in the age group of $65-80$ years, but not in other age groups. This may have been caused by referral bias; some elderly patients may not have been referred to our tertiary care centre. However, this probably does not severely affect the findings, as the majority of patients over 80 years were treated conservatively and $90 \%$ died in hospital or had a poor outcome. In our series, GCS $<13$ on admission lead to a uniformly poor outcome, which was in accordance with previous data. ${ }^{[3,4,14,25]} \mathrm{ICH}$ volume was correlated with bad outcome in univariate analyses. ${ }^{[1,4,14]}$ We have earlier shown a similar association in a prospective randomized trial of early surgery vs. conservative treatment in patients with a deep hemispheric ICH. ${ }^{[11]}$ In the present study, prior medication ${ }^{[6]}$ or comorbidities ${ }^{[2]}$ did not affect the outcome.

As previously suggested, hydrocephalus was associated with poor functional outcome or death in univariate analyses, ${ }^{[20,25]}$ although it did not reach statistical significance in the multivariate model. We used the criteria for "tight posterior fossa" (effacement of the basal cisterns combined with obstructive hydrocephalus) as an indirect measure of brainstem compression. ${ }^{[26]}$ It was associated with poor outcome in univariate analyses, but not in the multivariable model. ${ }^{[3,5]}$ Degree of fourth ventricle obstruction ${ }^{[13]}$ and quadrigeminal cistern obliteration ${ }^{[24]}$ were also associated with poor outcome or mortality at discharge in the univariate analyses, but not in the multivariable model. Fourth ventricle obstruction is usually considered the root cause of acute hydrocephalus in patients with a cerebellar ICH, and quadrigeminal cistern obliteration can be seen as a measure of mass effect in the posterior fossa.

It has also been suggested that vascular territory (SCA/ AICA/PICA) would affect the prognosis. ${ }^{[18]}$ In our series, patients with a hematoma in the AICA territory had the worst outcome, probably caused by the frequent hematoma extension into the brainstem. Location in the cerebellar anterior vs. posterior lobe had an effect on patient outcome only, if the hematoma extended to both the anterior and posterior cerebellar lobes. The same applied when considering the location of the hematoma in the cerebellar hemisphere vs. vermis. These observed effects were probably mainly caused by the greater hematoma volume in both situations.

We detected a trend, although not statistically significant, toward lower in-hospital mortality in the surgically treated patients. However, operated patients who survived were more often left in a poor condition. In addition, the long-term mortality did not differ between the medically and surgically treated patients. Unfortunately, we do not have long-term data on functional outcome of the surviving patients. There are very few reports on functional recovery after cerebellar ICH. It has been shown that moderately disabled patients with cerebellar ischemic stroke recovered well, but a poor clinical condition led to a poor rehabilitation outcome. ${ }^{[12]}$

Our series is the largest consecutive single-centre cohort published and it includes all patients with a spontaneous cerebellar ICH treated at our institute within a 5-year period. However, due to the observational and retrospective nature of the study, there may be some selection bias and inconsistency in the data. As there are no good guidelines, no protocol could be used to decide who should receive surgical treatment and who should not. Instead, the decisions were made case-by-case. The study was carried out in a tertiary level centre, and some patients may have been left in secondary hospitals due to suspected grim prognosis or died before arrival to the hospital, especially in the oldest age group. Unfortunately, we do not have long-term functional outcome data.

One of the most important findings in our study were the major differences between the surgically and medically treated patients. By using the current widely acknowledged criteria for surgical treatment (hemorrhage diameter $>30 \mathrm{~mm}$, declining level of consciousness, brainstem compression and/or hydrocephalus), all but the unsalvageable patients and the ones with a minor hemorrhage will undergo surgery. Consequently, the conservatively treated patients are healthier and less symptomatic, as severe symptoms and large hemorrhage volume lead to surgical treatment. Alas, it is rather impossible to gather a study population with two similar groups of patients that would have undergone surgical and conservative treatment.

Currently, no clinical equipoise exists on the surgical treatment of cerebellar hemorrhage (i.e., surgical treatment is currently considered superior in selected patients), and it surely prevents patients from dying, at least in the short-term. Due to the lack of clinical equipoise, it would be difficult to run a randomized controlled trial on operative treatment of cerebellar ICH. However, we are trying to support the previously published notion that the outcomes after surgery may not 
be as good as we neurosurgeons tend to think, and that the long-term functional outcome needs further studies because of the rather pessimistic short-term functional outcome and high long-term mortality. One possibility to assess the futility of the treatment would be to measure the long-term survivors' health-related quality of life in the surgically and medically treated patients.

\section{CONCLUSIONS}

Surgical treatment of cerebellar ICH can be life-saving but leads to a poor functional outcome. Lack of clinical equipoise makes designing randomized controlled trials difficult. New studies are needed on long-term recovery after a cerebellar ICH.

\section{Financial support and sponsorship Nil. \\ Conflicts of interest \\ There are no conflicts of interest.}

\section{REFERENCES}

I. Cohen ZR, Ram Z, Knoller N, Peles E, Hadani M. Management and outcome of non-traumatic cerebellar haemorrhage. Cerebrovasc Dis 2002; I4:207-I3.

2. Dahdaleh NS, Dlouhy BJ, Viljoen SV, Capuano AW, Kung DK, Torner JC, et al. Clinical and radiographic predictors of neurological outcome following posterior fossa decompression for spontaneous cerebellar hemorrhage. J Clin Neurosci 2012;19:1236-4I.

3. Dammann P, Asgari S, Bassiouni H, Gasser T, Panagiotopoulos V, Gizewski ER, et al. Spontaneous cerebellar hemorrhage-experience with 57 surgically treated patients and review of the literature. Neurosurg Rev 201 I;34:77-86.

4. Dolderer S, Kallenberg K, Aschoff A, Schwab S, Schwarz S. Long-Term Outcome after Spontaneous Cerebellar Haemorrhage. Eur Neurol 2004;52: I I 2-9.

5. Donauer E, Loew F, Faubert C, Alesch F, Schaan M. Prognostic factors in the treatment of cerebellar haemorrhage. Acta Neurochir 1994; 13 1:59-66.

6. Falcone GJ, Brouwers HB, Biffi A, Anderson CD, Battey TWK, Ayres AM, et al. Warfarin and Statins are Associated with Hematoma Volume in Primary Infratentorial Intracerebral Hemorrhage. Neurocrit Care 2013;21:192-9.

7. Fisher CM, Picard EH, Polak A, Dalal P, Ojemann RG. Acute hypertensive cerebellar hemorrhage: Diagnosis and surgical treatment. J Nerv Ment Dis 1965; | 40:38-57.

8. Flaherty ML, Woo D, Haverbusch M, Sekar P, Khoury J, Sauerbeck L, et al. Racial Variations in Location and Risk of Intracerebral Hemorrhage. Stroke 2005;36:934-7.

9. Han J, Lee HK, Cho TG, Moon JG, Kim CH. Management and Outcome of Spontaneous Cerebellar Hemorrhage. J Cerebrovasc Endovasc Neurosurg 2015; 17:185-93.

10. Hemphill JC, Greenberg SM, Anderson CS, Becker K, Bendok BR, Cushman M, et al. Guidelines for the Management of Spontaneous
Intracerebral Hemorrhage: A Guideline for Healthcare Professionals From the American Heart Association/American Stroke Association. Stroke 20I5;46:2032-60.

II. Juvela S, Heiskanen O, Poranen A, Valtonen S, Kuurne T, Kaste M, et al. The treatment of spontaneous intracerebral hemorrhage. A prospective randomized trial of surgical and conservative treatment. J Neurosurg 1989;70:755-8.

12. Kelly PJ, Stein J, Shafqat S, Eskey C, Doherty D, Chang Y, et al. Functional recovery after rehabilitation for cerebellar stroke. Stroke 200 I;32:530-4.

13. Kirollos RW, Tyagi AK, Ross SA, van Hille PT, Marks PV. Management of spontaneous cerebellar hematomas: A prospective treatment protocol. Neurosurgery 200I;49:1378-86.

14. Kobayashi S, Sato A, Kageyama Y, Nakamura H, Watanabe Y, Yamaura A. Treatment of hypertensive cerebellar hemorrhage--surgical or conservative management? Neurosurgery 1994;34:246-50.

I5. Kothari RU, Brott T, Broderick JP, Barsan WG, Sauerbeck LR, Zuccarello M, et al. The $A B C s$ of measuring intracerebral hemorrhage volumes. Stroke 1996;27:1304-5.

16. Little JR, Tubman DE, Ethier R. Cerebellar hemorrhage in adults. Diagnosis by computerized tomography. J Neurosurg 1978;48:575-9.

17. Luney MS, English SW, Longworth A, Simpson J, Gudibande S, Matta B, et al. Acute Posterior Cranial Fossa Hemorrhage-Is Surgical Decompression Better than Expectant Medical Management? Neurocrit Care 2016;25:365-70.

18. Matsukawa H, Shinoda M, Fujii M, Takahashi O, Yamamoto D, Murakata A, et al. Relationships among hematoma diameter, location categorized by vascular territory, and I-year outcome in patients with cerebellar hemorrhage. World Neurosurg 2012;77:507-II.

19. Meredith W, Rutledge R, Fakhry SM, Emery S, Kromhout-Schiro S. The conundrum of the Glasgow Coma Scale in intubated patients: A linear regression prediction of the Glasgow verbal score from the Glasgow eye and motor scores. J Trauma 1998;44:839-44.

20. Mezzadri JJM, Otero JM, Ottino CA. Management of 50 spontaneous cerebellar haemorrhages. Importance of obstructive hydrocephalus. Acta Neurochir 1993; 122:39-44.

21. Pong V, Chan K-H, Chong B-H, Lui W-M, Leung GK-K, Tse H-F, et al. Long-term outcome and prognostic factors after spontaneous cerebellar hemorrhage. Cerebellum 2012; 1 1:939-45.

22. Stein M, Luecke M, Preuss M, Boeker D-K, Joedicke A, Oertel MF. Spontaneous intracerebral hemorrhage with ventricular extension and the grading of obstructive hydrocephalus: The prediction of outcome of a special life-threatening entity. Neurosurgery 2010;67:1243-5I.

23. Steiner T, Al-Shahi Salman R, Beer R, Christensen H, Cordonnier C, Csiba L, et al. European Stroke Organisation (ESO) guidelines for the management of spontaneous intracerebral hemorrhage. Int J Stroke 2014;9:840-55.

24. Taneda M, Hayakawa T, Mogami H. Primary cerebellar hemorrhage. Quadrigeminal cistern obliteration on CT scans as a predictor of outcome. J Neurosurg 1987;67:545-52.

25. Tsitsopoulos PP, Tobieson L, Enblad P, Marklund N. Prognostic factors and long-term outcome following surgical treatment of 76 patients with spontaneous cerebellar haematoma. Acta Neurochir 2012; I54:I I89-95.

26. Weisberg LA. Acute cerebellar hemorrhage and CT evidence of tight posterior fossa. Neurology 1986;36:858-60.

27. Wijdicks EF, St Louis EK, Atkinson JD, Li H. Clinician's biases toward surgery in cerebellar hematomas: An analysis of decision-making in 94 patients. Cerebrovasc Dis 2000; 10:93-6.

28. Witsch J, Neugebauer H, Zweckberger K, Jüttler E. Primary cerebellar haemorrhage: Complications, treatment and outcome. Clin Neurol Neurosurg 2013; I1 5:863-9. 
Supplementary Table 1: Hematoma location in the medically, i.e., conservatively and surgically treated patients. We used Mann-Whitney $U$ test to test for statistically significant differences

\begin{tabular}{lccc}
\hline & Medical $(\boldsymbol{n}=\mathbf{7 6})$ & Surgical $(\boldsymbol{n}=\mathbf{3 8})$ & $\boldsymbol{P}$ \\
\hline Anterior lobe, $n(\%)$ & $17(22.4 \%)$ & $1(2.6 \%)$ & 0.002 \\
Posterior lobe & $47(61.8 \%)$ & $24(63.2 \%)$ & \\
Both & $12(15.8 \%)$ & $13(34.2 \%)$ & \\
Vermis & $14(18.4 \%)$ & $2(5.3 \%)$ & 0.001 \\
Hemisphere & $44(57.9 \%)$ & $16(42.1 \%)$ & \\
Both & $18(23.7 \%)$ & $20(52.6 \%)$ & \\
SCA & $47(61.8 \%)$ & $26(68.4 \%)$ & 0.941 \\
AICA & $10(13.2 \%)$ & 0 & \\
PICA & $12(15.8 \%)$ & $5(13.2 \%)$ & \\
Multiple & $7(9.2 \%)$ & $7(18.4 \%)$ & \\
\hline
\end{tabular}

SCA: Superior cerebellar artery,AICA:Anterior inferior cerebellar artery,

PICA: Posterior inferior cerebellar artery

Supplementary Table 2: The effect of hematoma location on poor functional outcome or mortality at discharge (modified Rankin Scale 4-6) in univariate logistic regression

\begin{tabular}{lccc}
\hline Variable & Odds ratio & 95\% CI & $\boldsymbol{P}$ \\
\hline Anteroposterior & & & \\
Anterior lobe & reference & & \\
Posterior lobe & 0.64 & $0.18-1.94$ & 0.444 \\
Both lobes & 15.86 & $1.52-2154$ & 0.017 \\
Laterality & & & \\
Vermis & reference & & \\
Hemisphere & 2.277 & $0.761-6.99$ & 0.138 \\
Both & 25 & $4.71-259$ & $<0.001$ \\
Vascular territory & & & \\
SCA & reference & & \\
AICA & 9.171 & $1.1-1198$ & 0.039 \\
PICA & 0.993 & $0.336-3.26$ & 0.99 \\
Multiple & 12.67 & $1.57-1644$ & 0.011 \\
\hline Cl: Confd
\end{tabular}

$\mathrm{Cl}$ : Confidence interval, SCA: Superior cerebellar artery,AICA:Anterior inferior cerebellar artery, PICA: Posterior inferior cerebellar artery 